\title{
POST-SECONDARY PAW PATROL: Effects of Animal-Assisted Activities on Students' Stress, Happiness and Well-being
}

\author{
Laura Sokal $^{1}$, Taylor Martin ${ }^{1}$ \\ ${ }^{1}$ Faculty of Education, University of Winnipeg, Canada \\ Correspondence: Faculty of Education, University of Winnipeg, Canada.
}

Received: Nov. 12, 2020

Accepted: Nov. 30, 2020

Online Published: Dec. 2, 2020

doi:10.11114/ijce.v4i1.5077

URL: https://doi.org/10.11114/ijce.v4i1.5077

\begin{abstract}
Two hundred forty-two students, including 76 college students and 166 university students from Canadian post-secondary schools, participated in a pre-post study of the effects of animal-assisted activities on their stress, happiness, and wellbeing. Findings showed that those students who had recently experienced a negative event showed significantly greater positive effects of the animal-assisted activities on all three dependent variables when compared with other students, although all students benefitted from participating in terms of desired effects on their stress, happiness, and well-being. In keeping with Keyes' model of mental wellness, these school-based, animal-assisted activities are supported as lowcost, low-stigma, universal approaches to mental health promotion.
\end{abstract}

Keywords: Animal-assisted activities, post-secondary, well-being, happiness, stress

\section{Introduction}

Many students enrolled in post-secondary schools concurrently fall within the developmental period of emerging adulthood-a transitional stage that comes with its own unique challenges. Emerging adults experience many life changes, such as completing their education, moving away from family and social supports, living alone or with new people, establishing careers, forming lifelong relationships, and dealing with new financial responsibilities (Henderson et al., 2018; Nunes et al., 2014). Because of the nature of these significant and often challenging life changes, it is no surprise that post-secondary students report struggling with stress and loneliness (ACHA-NCHA, 2019). Students within this age group also fall within the age range at the highest risk for psychological disability and substance use (Henderson et al., 2018). These recent statistics are further complicated by students being challenged by uncertainty and stress while navigating COVID-19.

Although post-secondary students do not struggle with mental health issues at a greater rate than non-students in the same age group (Wiens et al., 2020), there is a concerningly high prevalence of mental health issues among post-secondary students. A 2019 survey of post-secondary institutions in Canada found that in a 12-month period, $69 \%$ of student respondents had experienced overwhelming anxiety, $64 \%$ felt that things were "hopeless", $51 \%$ reported feeling overwhelming anger, $52 \%$ felt so depressed that they had difficulty functioning, and over $16 \%$ reported seriously considering suicide (ACHA-NCHA, 2019). Compared with the same report of Canadian university students three years prior, these statistics had increased within every category (ACHA-NCHA, 2016).

Despite the noteworthy prevalence of mental health issues in post-secondary students, few of these students report seeking help (ACHA-NCHA, 2019; Wada et al., 2019). One reason for this trend could be the stigma behind "mental illness" -which Wada et al. argued is a result of academic pressure, the concealed nature of these conditions, and mistreatment of people with mental illness (2019). This possibility points to a deeper problem that must be addressed by universities and colleges through awareness campaigns, dialogue, and better visibility for campus resources. Another reason for the low number of students seeking help is likely their limited financial resources. Nunes and colleagues' (2014) study of extended health insurance plans available to undergraduate students at 210 Canadian colleges and universities found that very few plans provided sufficient coverage for the treatment of common psychological health problems.

\subsection{Costs of Poor Mental Health in Post-secondary Schools}

Poor mental health in post-secondary students comes with costs, including financial and human costs. A common approach to addressing mental health needs on campus is referral the accessibility services (AS) offices. As a result, the 
accommodation needs of students with psychological disabilities are growing at a time when university budgets are strained, resulting in most (AS) offices being unable to keep up with the demand, despite additional funding (AUCCCD, 2014). Indeed, $93 \%$ of Canadian universities have increased their budgets to try to meet the mental health demands of their students, with the average increase being $35 \%$ over five years (Cribb et al, 2017). The latest Canadian college health findings (ACHA-NCHA, 2019) showed that $54.4 \%$ of post-secondary students had been treated for a disability within the last 12 months, including $34.6 \%$ reporting anxiety and $24.2 \%$ reporting depression, both at degrees severe enough to affect academic performance. Furthermore, some of these financial costs are borne by students who pay thousands of dollars for assessments that qualify them to receive accommodations based on disability status.

Without these accommodations, students with disabilities are less likely to complete post-secondary school, in turn generating more and broader costs: Statistics Canada (2014) showed the "difference [in employment rates] between university graduates with a mild or moderate disability and those without a disability was not significant" (p. 3). This finding suggests that university completion provides similar employment opportunities and protection to students with disabilities as to those without. In contrast, people with disabilities who do not hold university degrees face disproportionate chronic under-employment. Furthermore, when students with disabilities have unaddressed needs that result in incomplete post-secondary schooling, "society is deprived of their talent and their contribution to the economy" (Statistics Canada, 2014, p. 1).

Considered together, the costs of addressing student mental health needs through a reactive process of assessment, documentation and accommodation are high, as are the costs of not addressing these needs. Moreover, in promoting these reactive types of responses, the benefits are restricted to those students with diagnoses in place, including students with psychological disabilities like anxiety disorders. For at least six years, anxiety disorders have been and continue to be the most commonly reported condition of students who register with AS offices (AUCCCD, 2014, ACHA-NCHA, 2019). Furthermore, the 2016 ACHA-NCHA survey findings on Canadian post-secondary students showed that from 2013 to 2016, the prevalence of students with anxiety disorders increased by $50 \%$. Clearly, addressing anxiety disorders are driving university AS costs to a large degree. However, it is important to note that all students feel some levels of anxiety and stress as part of typical navigation of day-to-day student life, including exams, presentations, time management, and deadlines. In fact, $88.2 \%$ of Canadian students recently said they felt overwhelmed by all they had to do and, as previously mentioned, $68.9 \%$ felt overwhelming anxiety. It should be noted that not all of these students had psychological disabilities (ACHA-NCHA, 2019). By restricting services to students with documented disabilities, post-secondary schools miss addressing the mental health needs of the large population of students who do not have diagnoses but may also need supports to maintain mental health during post-secondary schooling.

\subsection{Reconceptualizing Mental Illness and Mental Health}

Attention to both students with and without diagnoses and to broader conceptualizations of mental illness and mental wellness are provided by the Keyes' (2005) model. Rather than viewing one continuum with mental wellness on one end and mental illness on the other, Keyes conceptualizes two separate and intersecting continua. The intersection creates four quadrants that capture both students with and without disabilities who are functioning well in daily life (called "flourishing" by Keyes) and both students with and without disabilities who are not functioning well in daily life (called "languishing" by Keyes). Conceptualizing adaptive functioning as a goal for both students with and without disabilities illuminates the limitations of reactive and restrictive services such as accessibility services. While these services are essential to the access and fairness for some students, to promote wellness in all students regardless of diagnosis, a different approach is needed. An approach to mental wellness that frames it within a strength-based rather than deficit perspective is supported by the Keyes' model as well as by the World Health Organization [WHO]: The WHO recognizes that mental health is not simply an absence of mental illness, but rather "a state of well-being in which an individual realizes his or her own abilities, can cope with normal stresses of life, can work productively and fruitfully, and is able to make a contribution to his or her community" (2004, p. 12). The 2019 ACHA-NCHA study supports the observation that many post-secondary students, both with and without diagnoses, are languishing.

Mental wellness can be enhanced by sustained efforts and self-determined actions, similar to practices and habits that contribute to physical health. If students are not seeking psychological help due to mental health stigma and/or cost (Nunes et al., 2014; Wada et al., 2019), then it is important to ensure that post-secondary institutions provide free, low-stigma programming to promote student mental wellness - programming that is accessible to both students with diagnoses and to those without. One way of promoting student mental health on post-secondary campuses is universal access to canine animal-assisted activities (AAA).

\subsection{Effects of School-based AAA on Student Mental Health}

Animal-assisted activities (AAAs), like animal-assisted therapy (AAT), fall under the broader umbrella of animal-assisted interventions. While AATs are planned and monitored by healthcare professionals with a defined therapeutic purposes 
and goals, AAAs are planned, informal interventions with educational, motivational, and recreational purposes (Ichitani \& Cunha, 2016). Since therapy dogs were first formally introduced in 2012 at the University of Ottawa (Dell et al., 2015), universities across Canada have started offering canine drop-in programs, which are a form of animal-assisted activities. These programs are typically regularly scheduled drop-in sessions, where any student is able to stop by and pet the animals. AAAs provide a cost-free and stigma-free component of mental health programming in universities.

Copious research has supported the benefits of having canine drop-in programs as a regular service offered by universities and colleges. In a 2018 study, Binfet, Passmore, Cebry, Struik, and McKay examined a weekly drop-in, canine therapy program in a western Canadian university to assess the stress-reducing effects of the program. Results indicated that participants' self-reported stress levels were significantly lower after the canine therapy intervention. Assessing two similar programs held in 2015 and 2016, Binfet also found that students did not need to spend a long time interacting with the animals, but gained similar benefits from only brief visits with the therapy dogs (Binfet, 2017).

Similarly, a 2016 study of college students during final exams looked at perceived stress levels of students before and after interacting with the therapy dogs, while adding a physiological dependent variable to the design. Although there were no significant changes in physiological stress levels, perceived stress significantly declined following the human-canine interactions (Barker, Barker, McCain, \& Schubert, 2016). A study on the use of animal-assisted activities in undergraduate students in Singapore found that there were not only psychological but also physiological benefits to well-being in students. After an hour-long AAA session, results indicated that students experienced significant decreases in state anxiety, and in systolic and diastolic blood pressure. Furthermore, state self-esteem increased post-AAA (Muckle \& Lasikiewicz, 2017).

These studies are supported by the findings of Dell et al. in a 2015 evaluation study of the St. John Ambulance (SJA) Therapy Dog Program on three university campuses in Canada. This program consists of trained and screened handlers and dogs, who are required to go through an orientation, evaluation and placement, which is supervised by an SJA representative (Dell et al., 2015). It is interesting to note that, unlike some other therapy dog programs, the SJA Therapy Dog program has specific goals that can be operationalized and measured. The Therapy Dog program has two goals: to offer (a) support and (b) love to the individuals with whom the dogs and handlers visit (St. John Ambulance as cited in Dell et al., 2015). In Dell et al.'s study, the researchers found, “...the therapy dogs unequivocally offer love and support to the students" (2015, p. 354) and students often used the words "love" and "support" to describe their experiences. These goals of love and support are relevant to the mental health needs of post-secondary students, as recent mental health surveys have shown that students are indicating feelings of loneliness and helplessness (ACHA-NCHA, 2019).

It is evident that post-secondary students need increased mental health support, and that AAAs offer major overall wellness benefits. Not only do these programs offer a broad range of students "love and support," but they are also a free, safe, low pressure and low commitment alternative to other student services. Perhaps most importantly, these programs normalize mental health and wellness practices and encourage students to take advantage of self-care opportunities.

Given that counselling and student psychological services often experience long wait times and are not widely accessible, Jaworska and colleagues' 2016 national survey on mental health services at Canadian post-secondary institutions noted that there is a significant need for services that reduce student stress and promote self-care. Mental health is closely tied to overall well-being, and services like AAAs, that reduce stress and encourage self-care, encourage a sense of overall well-being that may assist with mental health issues if they arise.

\section{Research Questions}

Given that post-secondary students typically encounter many changes and challenges during this developmental period, and in light of the potential mediating effects of AAAs, we investigated the following three questions:

\subsection{Question 1}

When considering the self-reports of students, will students with challenging circumstances demonstrate significantly lower levels of happiness and well-being and higher levels of stress than other students who report neutral or positive circumstances prior to school-based, canine AAA events?

\subsection{Question 2}

Are AAA activities sufficient to ameliorate the effects of challenging circumstances so that students who have experienced them demonstrate no significant differences in levels of happiness, well-being and stress after a school-based, canine AAA event than do students with prior neutral or positive circumstances?

\subsection{Question 3}

When considering the self-reports of students in three groups, will students with challenging circumstances demonstrate equal gains in levels of happiness and well-being and equal decreases in levels of stress during a school-based, canine AAA event when compared to other students who report prior neutral or positive circumstances prior to the event? 


\section{Methods}

\subsection{Study Design}

The current study was approved by the UHREB at the primary researchers' university and a certificate was issued (HE13453). As part of a larger study of the effects of touch on student responses to AAAs (Sokal, Martin, \& Bartel, under review), the current study examined the effects of animal-assisted activities in the form of canine animals visits on categories of post-secondary students at a university and a college, both centrally located in Canada. The AAA program was organized by the students' union at the university and by the student services office at the college, and organizational permissions to conduct the research were secured in each setting. In both cases, the animal visits were advertised and took place in a separate area that students needed to enter in order to visit with the animals. No appointments were necessary, and students were free to visit the animals for as long as they chose over the 1.5 hours available at each visit.

The animals/handler pairs were six volunteer teams from St. Johns Ambulance. This program issues certificates after the animals (both alone and with their handlers) have passed rigorous testing. Previous research (Dell et al., 2015) has provided detailed descriptions of these vetting processes. The animal/handler teams in this program are required to complete a minimum number of hours each month in order to maintain certification.

When students entered the AAA room, they were approached by an RA who invited them to take part in the research study. Interested students filled out an inventory asking for demographic information as well as questions related to their stress, happiness, and well-being. After visiting with the animals, the students were again asked to fill out the test instrument and provided with a five-dollar cash incentive.

\subsection{Instruments}

The inventory was designed to measure perceived stress, happiness, and well-being and has been described as part of the larger study (Sokal, Martin, \& Bartel, under review) and in previous AAA research involving different animals in an international setting (Sokal \& Kahl, 2019). Given that many inventories used in similar studies ask students to indicate how often they have felt a certain way (e.g. upset, unimportant) over a specific duration of time, it was important that we chose an inventory that could measure short-term change, as this was the focus of our study. With awareness of research by Linton, Dieppe, \& Medina-Lara (2016) that cautioned about differences between the constructs of well-being and state happiness, we chose to revise the World Health Organization's WHO5 measure of well-being. This measure has been validated in over 200 studies (Topp, Østergaard, Søndergaard, \& Bech, 2015) and furthermore is based on the World Health Organization's (2005) constitutional definition of health used as the framework of the current study. The original WHO5 is comprised of five statements and asks respondents to rate how often they have felt specific ways over the past two weeks. We retained the first four of the five statements, but asked the students to rate how they were feeling "right now" each time they filled out the survey (before and after AAA). Example statements included, "I feel cheerful and in good spirits" and "I feel calm and relaxed." Students responded on a six-point scale, with 6 indicating Strongly agree and 1 indicating Strongly disagree. We omitted the fifth statement, "My daily life has been filled with things that interest me," as it inferred a longer reference point and more generality than did the first four statements. Instead, we added two statements: "I am happy," and "I am stressed," which were measured using the same six-point scale. Single-item measures has been used successfully in the past by other researchers in AAA studies (see, Barker et al., 2016; Binfet et al., 2018) and in other research assessing a global construct such as stress (Eddy, Herman, \& Reinke 2019; Zimmerman et al., 2006).

At the pre-AAA administration of the measures, students were asked on the form to indicate if any events in particular were affecting their mood. If so, they were asked to classify the event as positive or negative and to provide a sentence summarizing the event.

\subsection{Participants}

Over the course of four data collections at AAA events at a university and one data collection at a college AAA event, 242 students participated, and these included 76 college students and 166 university students who provided informed consent and completed the study. The participants were 91 males, 136 females, 7 others, and 8 students who did not indicate gender. Most students (53.2\%) were in their first year of school, and $83.5 \%$ of the students were in their first three years of post-secondary attendance. Most of the students $(65.3 \%)$ lived in the city in which the institutions were located, although $17.8 \%$ lived rurally. A minority of students (13.1\%) indicated they were international students. Of the students who visited the sessions, $69.2 \%$ had a pet, and $57.8 \%$ lived with their pet. When asked at the onset of the study whether a recent event was affecting their mood, $38.2 \%(n=87)$ indicated that a negative recent event was affecting their mood, and $18.4 \%(n=42)$ indicated that a positive recent event was affecting their mood. Ninety-nine students indicated that no recent events were affecting their mood (43.4\%), and 14 did not respond to this question. Representative descriptions of negative events included: exams and tests (by far the most commonly mentioned negative events), depression, anxiety, and feeling sick. Positive events were represented by descriptors such as: a lab going well, being 
treated to lunch by a friend, receiving a birthday gift, spending time with a partner, good test performance, and anticipating a sporting event later in the day.

\section{Findings}

In order to address the three research questions, a MANOVA was conducted to determine whether there were differences in the dependent variables (well-being, stress, happiness) between (a) students who had a recent negative event affecting their mood, (b) students who had a recent positive event affecting their mood, and (c) students who did not report that a recent event was affecting their mood.

In terms of question 1, which referenced the students in the three event statuses before the AAA, the MANOVA revealed significant differences in all three dependent variables of well-being, $F(2)=21.16, p=.00$; stress, $F(2)=22.01, p=.000$, and happiness, $F(2)=15.09, p=.000$. Follow-up LSD $t$-tests and means analyses indicated the students who had had negative experiences were feeling significant less happiness, a lower sense of well-being, and higher stress compared with students in the other two groups. Means are presented in Table 1.

After the AAA event and in response to question 2, the MANOVA again revealed group-based differences in all three dependent variables of well-being, $F(2)=4.61, p=.011$; stress, $F(2)=10.74, p=.000$, and happiness, $F(2)=7.47, p=.001$. Follow-up LSD $t$-tests and means analyses indicated the students who had had negative experiences were feeling significantly less happiness when compared to the no event group but not to the positive event group; and significantly higher stress and lower well-being compared with students in the other two groups. Together, these findings indicate that the canine-based, AAA event was insufficient in 'leveling the playing field' between students who experienced positive, negative, and neutral events prior to the AAA event.

Table 1. Means and standard deviations for event groups during AAA activities

Previous event category

\begin{tabular}{|c|c|c|c|c|c|c|}
\hline & \multicolumn{2}{|c|}{$\begin{array}{l}\text { Positive event } \\
(n=42,18.4 \%)\end{array}$} & \multicolumn{2}{|c|}{$\begin{array}{l}\text { No event } \\
(n=99,43.4 \%)\end{array}$} & \multicolumn{2}{|c|}{$\begin{array}{l}\text { Negative event } \\
(n=87,38.2 \%)\end{array}$} \\
\hline & Mean & $S D$ & Mean & $S D$ & Mean & $S D$ \\
\hline \multicolumn{7}{|c|}{ Mean before AAA } \\
\hline Well-being & 4.24 & 0.90 & 4.03 & 0.84 & 3.37 & 0.82 \\
\hline Stress & 3.29 & 1.35 & 3.65 & 1.33 & 4.64 & 0.91 \\
\hline Happiness & 4.88 & 0.78 & 4.69 & 0.90 & 4.08 & 0.99 \\
\hline \multicolumn{7}{|l|}{ Mean after AAA } \\
\hline Well-being & 4.84 & 0.72 & 4.81 & 0.74 & 4.49 & 0.79 \\
\hline Stress & 2.22 & 1.04 & 2.25 & 1.07 & 2.95 & 1.24 \\
\hline Happiness & 5.27 & 0.92 & 5.51 & 0.63 & 5.01 & 1.07 \\
\hline \multicolumn{7}{|l|}{ Mean change } \\
\hline Well-being & 0.60 & 0.69 & 0.78 & 0.68 & 1.12 & 0.80 \\
\hline Stress & -1.07 & 1.03 & -1.40 & 1.26 & -1.69 & 1.16 \\
\hline Happiness & 0.39 & 1.02 & 0.82 & 0.78 & 0.93 & 1.34 \\
\hline
\end{tabular}

While the differences in the three event status groups that appeared both before and after the AAA event might suggest that students who have had negative events do not benefit from AAA to the same degrees as others, the MANOVA revealed that this was not the case. The MANOVA revealed that there were significant differences in the magnitude of change in all three variables over the course of the AAA between the groups in all three dependent variables including well-being $F(2)=8.39, p=.000$, stress $F(2)=3.23, p=.041$, and happiness $F(2)=3.17, p=.044$. Follow-up LSD $t$-tests with $p$ set at .05 were supplemented with examination of the means and indicated (a) significantly greater gains in well-being in the 
group who reported a negative recent event than in both the group reporting a positive recent event and the group who reported that no recent event was affecting their mood; (b) significantly larger decreases in stress for the group who reported a prior negative event when compared to the group who reported a prior positive event; (c) significantly greater gains in happiness in the group who reported a prior negative event when compared with the group who reported a prior positive event. In fact, the negative event group's mean happiness and well-being was higher and their stress was lower after the AAA event than they were for either other group before the AAA event, suggesting AAA served a compensatory function to the students experiencing negative events.

Given the group differences in responses to the AAA events, we conducted pre-post follow-up paired $t$-tests to determine whether members of each of the three groups demonstrated significantly different scores before and after the AAA event. Results indicated that all three groups demonstrated significantly greater well-being and happiness and lower stress after the AAA event when compared with their scores before the event. Please see Table 2.

Table 2. Results of pre-post paired t-tests by event group

\begin{tabular}{llll}
\hline Group/Variable & & Result & \\
\hline & $d f$ & $t$ & $p$. \\
Positive event group & & & .000 \\
Well-being & 41 & -5.62 & .011 \\
Happiness & 41 & -2.67 & .000 \\
Stress & 40 & 6.88 & \\
Neutral event group & & & .000 \\
Well-being & 97 & -11.31 & .000 \\
Happiness & 97 & -10.38 & .000 \\
Stress & 97 & 11.00 & .000 \\
Negative event group & & & .000 \\
Well-being & 86 & -13.11 & .000 \\
Happiness & 85 & -6.46 & \\
Stress & 86 & 12.98 & \\
\end{tabular}

\section{Discussion}

Analyses revealed a number of interesting findings, some of which were expected and some of which were surprises. First, the findings revealed that a large percentage of students cited negative experiences that affected their moods. At the study's onset, almost two in five students felt that a recent negative event was significant enough to affect them, while only one in five students cited positive experiences. The self-reported scores of well-being, stress, and happiness before the AAA event mirrored the perceptions of the effects of recent events, as they followed the trend of students who reported negative recent experiences demonstrating the highest stress and the lowest well-being and happiness scores; the students who reported positive recent experiences demonstrating the lowest stress and the highest well-being and happiness scores; and the students who reported neither recent positive or negative events scoring somewhere in the middle. While it is possible that students with low happiness and well-being and high stress are disproportionately drawn to the AAA events, when considered alongside recent research about low levels of student mental health (ACHA-NCHA, 2016, 2019; Cribb et al., 2017), it is more likely that this finding is an artifact of the current general state of student mental wellness. It is noteworthy that situations that some people might navigate as the regular bumps along the road of life were significant enough to affect the students in ways they felt worthy of reporting. Exemplars from our study are: "friends being dumb," "so many assignments," "bad sleep last night," "my phone broke" or "exams" and "tests." Other research has indicated that examinations are the most common stressful event cited by university students (Pierceall \& Keim 2007; Robothan \& Julian, 2006), and that observation was borne out in our findings as well. Moreover, some students cited relatively more serious issues such as "general depression," or "a sick grandparent" as affecting their mood in a negative way. Together, these findings confirm that current post-secondary students are navigating a broad range of challenges while attending schooling and that these challenges affect their perceptions of happiness, well-being, and stress. Moreover, the students' comments indicated that the AAA events are accessed by both students with and without diagnoses, as some students 
cited mental health diagnoses in their description of events, confirming that AAAs are being used as universal strategies by students with a range of mental health statuses.

Second, the observation that a rising tide raises all ships is certainly evident in our study and is demonstrated by the significant, pre-post treatment differences for all groups and with all variables found in Table 2. While students in all groups benefitted in lowering stress and increasing happiness and well-being, it is noteworthy that the students who started out with the least desirable scores in these areas also made the greatest positive change. In fact, their final stress, happiness, and well-being scores at the endpoint of the AAA event were more positive than were the scores of the other two groups before the event (see Table 1), suggesting that AAAs serve to ameliorate the effects of negative events on students' happiness, stress, and well-being. Together, these findings show that even short, relatively inexpensive interventions such as AAA can provide meaningful protective influence on students, but this is especially true of students who are struggling within a range of experiences they perceive as negative.

Given that research has suggested that students struggle with mental health issues even more so in current times than in the past (ACHA-NCHA, 2016, 2019; Cribb et al., 2017), and that mental health issues are harbingers of other worrisome outcomes such as academic failure, unemployment, and addictions (Eisenburg, Gollust, Golberstine, \& Hefner, 2007), the opportunity to mitigate poor mental health in students cannot and should not be ignored. Offering campus-based programming like AAA is broadly appealing and therefore encourages students to seek experiences that moderate the transition to adult life. AAAs circumvent the challenges of convincing students to participate-- a common issue with other types of mental health interventions, such as therapy or use of student accessibility services. These approaches sometimes carry a negative stigma that can lead students to feel a sense of shame for seeking assistance (Sokal \& Desjardins, 2016). With AAAs, students are self-motivated to seek experiences that help them balance life's challenges, and their responsibility to access these sorts of opportunities becomes normalized rather than stigmatized. Furthermore, these opportunities are available to all students without pre-assessment or cost, so they address the key principle of the Keyes' (2005) model in terms of the need for everyone to seek opportunities that promote "flourishing." The agency that students demonstrated in attending AAA is indicative of their self-determination (Ryan \& Deci, 2000). Self-determination is recognized as an essential attribute in successful post-secondary educational outcomes, but even more so for students with additional challenges (Field, Sharver, \& Shaw, 2003; Getzel, 2008). In seeking experiences to promote mental wellbeing and decrease stress, students become leaders rather than followers in maximizing their own mental health.

\subsection{Limitations}

Despite the overall positive findings of our research study, we must acknowledge that all research has limitations and ours is no exception. These limitations relate to the study design itself, as well as its application of findings. There are two design issues that should be noted. First, there are ethical considerations involved in using animals in this way. While AAAs are common in North America, most European post-secondary institutions do not offer them. When asked about this decision, Rainer Wohlfarth-- who is President of the European Society for Animal Assisted Therapy (personal communication July 11,2019) -- said that it was viewed as unethical to use animals only for human comfort. The current project design offered some mitigation of the issue of using animals, in that the animals were family pets with limitations on their working hours, and their owners were vetted and trained in recognizing animals stress. In our observations, we noted several animal guardians curtail AAA visits when they noticed signs of stress in their dogs. Most research has suggested that animals who participate in these types of programs do not demonstrate negative effects based on both observational and biological data (Glenk et al., 2013; Palestrini at al., 2017), but this consideration should remain at the forefront in both AAA research and programs.

A second limitation of the research design is that it depends on self-reported data. More objective supplemental data sources would strengthen our confidence in the results, and research is beginning to explore the physiological effects of touching animals on humans' cortisol to establish this relationship empirically (Kertes et al., 2017). Moreover, the current study examined perceived stress, happiness and well-being, so self-reported data are appropriate to these goals. Considered together, we find some mitigation of the limitation of self-reported data in our study.

There are three limitations on the application of these findings. First, we should be cognizant that this study looked at broad populations of students. While some of these students mentioned they had psychological disabilities, it should not be inferred that a campus-based AAA program alone would be the ideal response to the needs of these students. Moreover, we measured only short-term effects, and these should not be interpreted as anything more. Second, while the students who participated in the study chose to take part and in fact sought contact with dogs, it is important to remember that not all students would do so due to fear or allergies or religious reasons for not touching dogs. For these students, other AAAs involving other types of animals or other types of approaches for promoting mental wellness might be more suitable. Our final consideration in terms of application of the findings relates to other uses of comfort animals on campuses. Our study took place in closed spaces where participants were given the choice of whether they wanted to be around the dogs or not. 
As more and more students find comfort in their own animals, post-secondary campuses are faced with developing new policies that respect both the accommodation needs of these students as well as the allergies and fear of the other students in common spaces such as dormitories and classrooms (Masinter, 2015). Based on these three concerns as well as on concern for animal welfare, AAAs should be considered carefully before being implemented into post-secondary schooling.

\section{Conclusions}

Notwithstanding these limitations in design and application, our results suggest that short-duration, campus-based AAAs can assist students with better well-being and happiness and lower stress, but this is especially important to students facing challenging negative circumstances. Given the uncertainty and social isolation that students have faced during the current pandemic, it is likely that the return to school will introduce new stress to some students. By offering universal programming such as AAA, student services administrators can address the academic and mental wellness needs of both students with diagnosed disabilities but also those with no diagnoses. This is an important aspect of WHO's (2004) and Keyes' (2005) key claims that all students can improve their mental wellness.

\section{Acknowledgements}

We gratefully acknowledge Brianne Bartel, the students and administrators at the post-secondary institutions who took part in this study, and the research support of the Social Sciences and Humanities Research Council of Canada in the form of an Explore grant.

\section{References}

American College Health Association [ACHA-NCHA] (2016). National College Health Assessment Canadian Reference Group. http://campusmentalhealth.ca/resource/aucccd-annual-survey/

American College Health Association [ACHA-NCHA] (2019). National College Health Assessment Canadian Reference Group. http://www.cacuss.ca/files/Research/NCHA-iiSpring

Association for University and College Counseling Centre Directors Annual Survey [AUCCCD]. (2014). AUCCCD Monograph Public 2013. http://files.cmcglobal.com/AUCCCD_Monograph_Public_2013.pdf

Barker, S., Barker, R. T., McCain, N. L., \& Schubert, C. M. (2016). A randomized cross-over exploratory study of the effect of visiting therapy dogs on college student stress before final exams. Anthrozoos, 29, 35-46. https://doi.org/10.1080/08927936.2015.1069988

Binfet, J. T. (2017). The effects of group-administered canine therapy on university students' wellbeing: A randomized controlled trial. Anthrozoös, 30(3), 397-414. https://doi.org/10.1080/08927936.2017.1335097

Binfet, J., Passmore, H., Cebry, A., Struik, K., \& McKay, C. (2018). Reducing university students' stress through a dropin canine-therapy program. Journal of Mental Health, 27(3), 197-204. https://doi.org/10.1080/09638237.2017.1417551

Cribb, R. Ovid, N., Lao, D., \& Bigham, B. (May 29, 2017). Demand for youth mental health services is exploding. How universities and business are scrambling to react. Toronto Star, n.p. https://www.thestar.com/news/canada/2017/05/29/youth-mental-health-demand-is-exploding-how-universitiesand-business-are-scrambling-to-react.html

Crossman, M. K. (2017). Effects of interactions with animals on human psychological distress. Journal of Clinical Psychology, 73(7), 761-784. https://doi.org/10.1002/jclp.22410

Dell, C. A., Chalmers, D., Gillett, J., Rohr, B., Nickel, C., Campbell, L., ... Brydges, M. (2015). PAWSing student stress: Pilot evaluation study of three university campuses in Canada. Canadian Journal of Counselling and Psychotherapy 49(4), 332-359.

Eddy, C., Herman, K., \& Reinke, W. (2019). Single-item teacher stress and coping measures: Concurrent and predictive validity and sensitivity to change. Journal of School Psychology, 17-32. https://doi.org/10.1016/j.jsp.2019.05.001

Eisenberg, D., Gollust, S. E., Golberstein, E., \& Hefner, J. L. (2007). Prevalence and correlates of depression, anxiety, and suicidality among university students. American Journal of Orthopsychiatry, 77, 534-542. https://doi.org/10.1037/0002-9432.77.4.534

Field, S., Sarver, M. D., \& Shaw, S. F. (2003). Self-Determination. Remedial \& Special Education, 24(6), 339. https://doi.org/10.1177/07419325030240060501

Getzel, (2008). Addressing the persistence and retention of students with disabilities in higher education: Incorporating key strategies and supports on campus. Exceptionality: A Special Education Journal, 16(4), 207-219. 
https://doi.org/10.1080/09362830802412216

Glenk, L., Kothgasser, O., Stetina, B., Plame, R., Kepplinger, B., \& Barren, H. (2013). Therapy dogs' saliva cortisol levels vary during animal-assisted interventions. Animal Welfare, 22, 369- 378. https://doi.org/10.7120/09627286.22.3.369

Henderson, L., Thompson, K., Hudson, A., Dobson, K., Chen, S., \& Stewart, S. (2018). An analysis of campus culture, mental health, and drinking at three Canadian universities. Canadian Journal of Community Mental Health, 37(3). https://doi.org/10.7870/cjcmh-2018-013

Ichitani, T., \& Cunha, M. C. (2016). Effects of animal-assisted activity on self-reported feelings of pain in hospitalized children and adolescents. Psicologia: Reflexao e Critica, 2(43). https://doi.org/10.1186/s41155-016-0049-1

Jaworska, N., De Somma, E., Fonseka, B., Heck, E., \& MacQueen, G. M. (2016). Mental health services for students at postsecondary institutions: A national survey. The Canadian Journal of Psychiatry, 61(12), 766-775. https://doi.org/10.1177/0706743716640752

Kertes, D., Liu, J., Hall, N., Hadad, N., Wynne, C., \& Bhatt, S. (2017). Effect of pet dogs on children's perceived stress and cortisol stress response. Social Development, 26(2), 382-401. https://doi.org/10.1111/sode.12203

Keyes, C. (2005). Mental illness and/or mental health. Investigating axioms of the complete state model of health. American Journal of Consulting and Clinical Psychology, 73(3), 539-548. https://doi.org/10.1037/0022006X.73.3.539

Linton, M., Dieppe, P., \& Medina-Lara, A. (2016). Review of 99 self-report measures for assessing well-being in adults: exploring dimensions of well-being and developments over time. BMJ Open, 6. e010641. https://doi.org/10.1136/bmjopen-2015-010641

Masinter, M. (2015). Consider your campus housing policy on emotional support animals in light of legal claims. Disability Compliance for Higher Education, 21(1), 3-3. https://doi.org/10.1002/dhe.30086

Muckle, J., \& Lasikiewicz, N. (2017). An exploration of the benefits of animal-assisted activities in undergraduate students in Singapore. Asian Journal of Social Psychology, 20, 75-84. https://doi.org/10.1111/ajsp.12166

Munsey, C. (2006). Emerging adults: The in-between age. American Psychological Association, 3(7), 68. https://doi.org/10.1037/e512802006-035

Nunes, M., Walker, J. R., Syed, T., Jong, M., Stewart, D., Provencher, M. D., ... Furer, P. (2014). A national survey of student extended health insurance programs in postsecondary institutions in Canada: Limited support for students with mental health problems. Canadian Psychology 55(2), 1-1-109. https://doi.org/10.1037/a0036476

Palestrini, C., Calcaterra, V., Cannas, S., Talamonti, Z., Papotti, F., Buttra, D., \& Pelizza, G. (2017). Stress level evaluation in a dog during animal- assisted therapy in pediatric surgery. Journal of Veterinary Behavior, 17, 44-49. https://doi.org/10.1016/j.jveb.2016.09.003

Pierceall, E., \& Keim, M. (2007). Stress and coping strategies among community college students. Community College Journal of Research and Practice, 31(9), 703-712. https://doi.org/10.1080/10668920600866579

Robotham, D., \& Julian, C. (2006). Stress and the higher education student: A critical review of the literature. Journal of Further and Higher Education, 30(2), 107-117. https://doi.org/10.1080/03098770600617513

Ryan, R. M., \& Deci, E. L. (2000). Self-determination theory and the facilitation of intrinsic motivation, social development, and well-being. American Psychologist, 55, 68-78. https://doi.org/10.1037/0003-066X.55.1.68

Sokal, L., \& Desjardins, N. (2016). What students want you to know: Supporting success in our students with anxiety disorders. Journal of Excellence in College Teaching, 27(3).

Sokal, L., \& Kahl, A. (2019). The effects of animal-assisted activities (AAA) on minority students at a boarding school in Germany. The McGill Journal of Education, 54(3). https://doi.org/10.7202/1069765ar

Statistics Canada (2014). Persons with disabilities and employment. Retrieved from http://www.statcan.gc.ca/pub/75006-x/2014001/article/14115-eng.pdf

Topp, C., Østergaard, S. D., Søndergaard, S., \& Bech, P. (2015). The WHO-5 Well-Being Index: a systematic review of the literature. Psychotherapy and Psychosomatics, 84(3), 167-76. https://doi.org/10.1159/000376585

Wada, M., Suto, M. J., Lee, M., Sanders, D., Sun, C., Le, T. N., ... Chauhan, S. (2019). University students' perspectives on mental illness stigma. Mental Health \& Prevention, 14(200159). https://doi.org/10.1016/j.mph.2019.200159

Wiens, K., Bhattarai, A., Dores, A., Pedram, P., Williams, J. V. A., Bulloch, A. G. M., \& Patten, S. B. (2020). Mental health among Canadian postsecondary students: A mental health crisis? The Canadian Journal of Psychiatry, 65(1), 
30-35. https://doi.org/10.1177/0706743719874178

World Health Organization. [WHO] (2004). Promoting mental health: Concepts, emerging evidence, practice. (Summary report). Geneva: Author.

Zimmerman, M., Ruggero, C., Chelminski, I., et al. (2006). Developing brief scales for use in clinical practice: The reliability and validity of single-item measures of depression symptom severity, psychosocial impairment due to depression, and quality of life. Journal of Clinical Psychiatry, 67, 1536-1554. https://doi.org/10.4088/JCP.v67n1007

Zivin, K., Eisenberg, D., Gollust, S. E., \& Golberstein, E. (2009) Persistence of mental health problems and needs in a college student population. Journal of Affective Disorders 117, 180-185. https://doi.org/10.1016/j.jad.2009.01.001

\section{Copyrights}

Copyright for this article is retained by the author(s), with first publication rights granted to the journal.

This is an open-access article distributed under the terms and conditions of the Creative Commons Attribution license which permits unrestricted use, distribution, and reproduction in any medium, provided the original work is properly cited. 